\title{
O FUTEBOL NOS BARES DE BELO HORIZONTE: O TORCER EM UMA CIDADE BOÊMIA
}

\author{
FOOTBALL IN BELO HORIZONTE BARS: FANS IN A BOHEMIAN CITY
}

\author{
EL FÚTBOL EN LOS BARES DE BELO HORIZONTE: LOS AFICIONADOS EN \\ UNA CIUDAD BOHEMIA
}

Felipe Vinícius de Paula Abrantes*, Silvio Ricardo da Silva*

\section{Palavras-chave} Futebol. Atividades de lazer. Antropologia cultural.
Resumo: Esta pesquisa objetivou analisar e discutir o torcer em bares de Belo Horizonte. Para isso, entendeu o torcer como importante manifestação de lazer da população belohorizontina, assim como a frequência aos inúmeros bares da capital mineira. Utilizamos as anotações em caderno de campo e entrevistas, a partir da inspiração etnográfica. A pesquisa mostrou que a transmissão das partidas nos bares é importante para os comerciantes, uma vez que têm a margem de lucro aumentada em dias de jogos. Foi possível observar que o encontro e a sociabilização com outros torcedores, a formação de vínculo com os proprietários e o consumo de bebida alcoólica são os principais fatores que levam as pessoas a torcer nos bares.

Resumen: Esta investigación tuvo como objetivo analizar y discutir la afición en los bares de Belo Horizonte. Entendiendo la afición como una importante manifestación de ocio de la población de Belo Horizonte, así como su presencia en los numerosos bares de la capital de Minas Gerais. Para ello, utilizamos anotaciones en cuadernos de campo y entrevistas, inspirados en la investigación etnográfica. La investigación permitió demostrar que la transmisión de los partidos en bares es importante para los comerciantes, que tienen las ganancias aumentadas en los días de juego. Se observó que el encuentro y socialización con otros aficionados, la formación de vínculos con los propietarios y el consumo de bebidas alcohólicas son los principales factores que llevan a las personas a los bares a asistir a la transmisión de los partidos.

Abstract: This study aimed to analyze and discuss rooting for football teams in bars in the city of Belo Horizonte. Rooting and attending the numerous bars in the city are seen as important leisure expressions for the population. We used field diary notes and interviews conducted under ethnographic inspiration. Research has shown that TV broadcasting of football matches is important for bar owners since their profits increase on those days. We observed that meeting and socializing with other fans, forming bonds with bar owners and consuming alcohol are the main factors that lead people to root for their teams in bars.
*Universidade Federal de Minas Gerais. Belo Horizonte, MG, Brasil. E-mail: felipevpa@yahoo.com.br

Recebido em: 27-06-2016 Aprovado em: 10-09-2016 (c) (1) (8) Licence 


\section{INTRODUÇÃO}

Futebol e cerveja. No imaginário popular, são duas das grandes paixões do brasileiro. Em certa medida, essa crença foi um dos motivos que nos levaram a investigar esse tema. Assim, a pesquisa que originou o presente artigo foi realizada entre julho de 2013 e julho de 2015, na cidade de Belo Horizonte e registrada junto ao Comitê de Ética em Pesquisa (COEP/ UFMG) com o parecer de número 948.127.

Não somente a cerveja, e não somente no Brasil, as bebidas alcoólicas de maneira geral compõem uma tríade - futebol-álcool-sociabilidade masculina - que, segundo o estudo do Weed (2007), é bastante comum.

Em um trabalho anterior, Weed (2006) aponta que os bares ganharam essa relevância com 0 advento do relatório Taylor ${ }^{1}$, que expôs os problemas de violência enfrentados na Inglaterra, e, a partir dele, os estádios britânicos passaram a ser mais controlados. Assim, segundo o pesquisador, os torcedores considerados torcedores-problema, como os hooligans, viram nos bares uma alternativa para a manutenção da sociabilidade que a experiência de torcer propiciava, até então, dentro dos estádios (WEED, 2006).

Sobre a relação entre torcedores e pubs ingleses, Dixon (2014) aponta que muitos torcedores reconhecem o bar como um local propício para acompanhar as partidas e torcer pelo seu clube de futebol. Segundo ele, um fator que influencia essa percepção é o julgamento que os torcedores fazem de que os estádios foram "santificados" e, assim, o bar, em uma hierarquia, acaba, muitas vezes, se colocando acima dos estádios.

No Brasil, essa realidade começa a se desenhar. Mesmo para aqueles torcedores que continuam presentes nas cadeiras e arquibancadas, a chegada com antecedência nos arredores dos estádios para consumirem cerveja é prática recorrente e a relação entre o torcer no futebol e o consumo da bebida alcoólica vem sendo reafirmada ao longo dos anos.

Vemos que, assim como o torcer, os bares se apresentam como uma possibilidade para a vivência do lazer, potencializada em uma cidade como Belo Horizonte, conhecida como a "Capital Nacional de Bares"2". Isto posto, defendemos que a frequência de belo-horizontinos a esses espaços não é um modismo, constitui-se como parte da cultura.

Belo Horizonte, desde a sua inauguração, tem como um de seus objetivos a busca pelo "moderno"3. O convívio social nas ruas e em outros espaços públicos foi incentivado entre os cidadãos que, apesar de toda essa onda modernizante, mostravam resistência e procuravam manter os hábitos provincianos, comuns em suas cidades de origem (SALLES, 2005).

O processo de urbanização da capital apoiou-se nas atividades de lazer para a implementação de um ethos moderno tão almejado. É nesse contexto que a presença de bares e cafés em Belo Horizonte (principalmente na região central) contribuiu para a criação de

\footnotetext{
1 Documento produzido e supervisionado por Lorde Taylor de Gosforth. Publicado em janeiro de 1990, trazia apurações de responsabilidades de um desastre em um jogo de futebol na semifinais da Taça da Inglaterra, bem como recomendações de segurança para futuros eventos esportivos.

2 Em junho de 2009, foi publicada a lei n. 9.714 pela Prefeitura de Belo Horizonte (PBH), que reconhece a cidade como a capital dos bares e define o dia municipal dos bares e botecos a ser comemorado sempre no terceiro sábado de maio. Segundo a Associação Brasileira de Bares e Restaurantes (Abrasel) e a RankBrasil, (empresa de recordes no país) BH tem a maior quantidade de bares por habitante. Com 12 mil bares a quantidade per capita é de 166 pessoas por bar na cidade. na Europa, principalmente em Paris, naquela época. Para maiores detalhes, consultar Salles (2005).
} 
uma vivência cultural, ainda não tão evidente, mas desejada, e por esse motivo esse tipo de comércio ganha relevância, além de econômica, social.

Outrora centralizados, atualmente vemos a existência de outros polos boêmios na capital mineira: ruas e bairros onde podemos encontrar bares que dão continuidade a essa tradição. Entendemos que, de fato, as experiências nesses lugares, antigos, novos, centrais ou periféricos, nos permitem entender o lazer como uma prática de sociabilidade, "[...] desencadeando a criação de laços e vínculos entre os indivíduos, além de influenciar na forma com que nos relacionamos com a própria cidade, entendendo-a, portanto, como um equipamento de lazer" (TORRES, 2008. p. 86).

Para nós esse tema apresenta relevância, pois conjuga duas importantes manifestações de lazer em Belo Horizonte, a ida a bares e o torcer no futebol. Damo (2007) ressalta que, para algumas pessoas, o torcer passa a ter um significado de identificação forte.

Diante do exposto, o objetivo com o presente texto é analisar a vivência do torcer em bares de Belo Horizonte, bem como os motivos que levam os torcedores a torcer no bar e quais os impactos que essa atividade traz para os comerciantes, estabelecimentos e torcedores.

\section{DECISÕES METODOLÓGICAS}

Elencamos cinco bares de diferentes regiões de Belo Horizonte. Durante 2014 foi realizado o trabalho de campo. Lançamos mão de diferentes ferramentas para coleta de dados, foram elas: a observação participante, as anotações em caderno de campo (MINAYO, 1994), a aplicação de questionários com torcedores e a realização de entrevistas semiestruturadas com torcedores e proprietários dos estabelecimentos que fizeram parte da pesquisa. A priori, buscamos os bares em que tínhamos o conhecimento prévio de serem locais de encontro das torcidas de Atlético e Cruzeiro. Neste esforço, acabamos nos deparando com outros possíveis locais igualmente interessantes como os imaginados de antemão. Desta forma, caracterizou-se, mesmo que minimamente, uma forma de entrada no campo afeita aos estudos de cartografia em que:

[...] não existe um campo constituído a priori operando uma 'coleta de dados' como se os dados estivessem prontos para serem coletados [...] no início de uma pesquisa constituímos pontos de entrada para o campo, sendo o seu percurso delineado ao longo da pesquisa, no encontro do pesquisador-cartógrafo. A pesquisa passa a operar assim, tal qual um rizoma: como múltiplas possibilidades de entradas e saídas (ZAMBENEDETTI; SILVA, 2011, p. 457).

Situação emblemática foi na escolha do bar Galopé \& Cia, onde pesquisamos a torcida em jogos do Atlético. Ainda buscando locais para a realização da pesquisa, passamos em frente ao referido bar durante uma partida e vimos o bar tomado de torcedores. 0 estabelecimento estava caracterizado com bandeiras alvinegras e ouviam-se cânticos como se fora em um estádio. Assim, o bar Galopé \& Cia, situado na Regional Norte de $\mathrm{BH}$, integrou-se à pesquisa. Os outros quatro bares escolhidos também seguiram critérios parecidos. No Bar do Paulinho 0 destaque é o dono do bar, um cruzeirense fanático, que torna esse estabelecimento um ponto de reunião de torcedores celestes na Regional Noroeste da capital mineira. Assim como no Bar do Paulinho, o Bar do João tem a característica de possuir um "dono-torcedor-fanático". Porém, João é atleticano e aglutina em seu bar, na região da Savassi, vários torcedores do Galo ${ }^{4}$ 
durante as partidas. Na mesma região, foi pesquisado o Itatiaia Rádio Bar, comércio ligado à Rádio Itatiaia. Finalmente, o Bar Pompéu na Regional Pampulha, onde o fato mais curioso é a transmissão simultânea dos jogos de Atlético e Cruzeiro, quando ocorrem no mesmo momento. A incursão aos bares foi realizada nos jogos finais do Campeonato Mineiro, durante a Libertadores, a Copa do Brasil e o Campeonato Brasileiro. Foram 42 idas a campo em jogos do Atlético e 45 em jogos do Cruzeiro, 73 questionários aplicados e realizadas oito entrevistas semiestruturadas, sendo quatro com torcedores e quatro com proprietários dos bares.

\section{QUANDO O CAMPO É O BOTECO: ANÁLISE DOS BARES SELECIONADOS}

Em todos os bares é possível perceber que, em dias de jogos, há uma organização não habitual do modo de funcionamento do estabelecimento ${ }^{5}$. Bem como o freguês-torcedor ali presente se comporta e interage diferentemente do freguês que não está ali pelo futebol. Percebemos que, pelo menos durante a partida, não é a cerveja ou o tira gosto, mas, sim, o futebol que será a "especialidade da casa" para o freguês-torcedor.

Com as observações que realizamos e tendo como base os estudos de Magnani (2002; 2008), é possível entender que, pela forma de vivenciar o bar, para muitos torcedores, esses estabelecimentos podem ser considerados como um "[...] pedaço" (MAGNANI, 2008, p.33), principalmente quando há uma predileção explícita do proprietário com o clube, Atlético ou Cruzeiro. Os torcedores identificam e elegem o espaço como lugar propício para acompanhar as partidas dos clubes, caso que evidenciamos nos dois primeiros bares analisados, o Bar do Paulinho e o Bar do João.

\subsection{Bar do Paulinho}

O Bar do Paulinho se encontra na Regional Noroeste, no bairro o Coração Eucarístico. O bairro tem muitos bares que são frequentados por estudantes da PUC-MG. O Bar do Paulinho destoa, porém, dos demais e tem como clientela moradores antigos e com a faixa etária mais elevada. O Bar do Paulinho está localizado em uma via movimentada, o que acarreta, em muitos momentos, a manifestação de outros torcedores que, passando com carros e motos perto do comércio, veem a concentração do grupo de cruzeirenses em dias de jogos.

Quando o Cruzeiro marca um gol, a manifestação dos torcedores, de maneira geral, se repete. Praticamente todos eles comemoram dando um entusiasmado grito e se levantando da cadeira. Alguns se cumprimentam, elogiam a jogada ou o gol.

Uma característica que é marcante no Bar do Paulinho é a presença quase exclusiva de torcedores do gênero masculino, corroborando Gastaldo (2006), que considera a assistência ao futebol no espaço dos bares não somente majoritariamente masculina, mas também um relevante lugar simbólico para a construção/manutenção de uma identidade masculina hegemônica. $\mathrm{O}$ grupo de torcedores que frequenta o bar em dias de jogos é praticamente 0 mesmo, e procura sentar-se para assistir às partidas nos mesmos lugares.

Quando há partida do Atlético e do Cruzeiro, no mesmo dia e horário, Paulinho opta por passar os dois jogos. No entanto, Paulinho, como um bom "cruzeirense chato" ("título" concedido 
pelos clientes mais antigos de Paulinho), opta por passar o jogo do Atlético na TV que fica no interior do bar, onde a concentração de torcedores é menor. 0 jogo é ainda transmitido sem 0 áudio, ao contrário do televisor que transmite a partida do Cruzeiro. Origuela (2013) observou situação semelhante em seu trabalho. Segundo relata, apenas o jogo do time da capital tem a transmissão com a narração. Enquanto o jogo do clube do interior paulista tem sua partida transmitida na televisão menor e sem o volume. "Duas TVs estavam ligadas. Na TV principal, a maior, o jogo televisionado era São Paulo e Mirassol com o áudio. Na TV menor passava União Barbarense e XV de Piracicaba, sem o áudio" (ORIGUELA, 2013, p. 63).

Mesmo sendo um bar reconhecido como um território cruzeirense, o bar também conta com a presença de torcedores atleticanos. A convivência entre os rivais é pacífica. Durante todo o período da pesquisa não foi observado nenhum tipo de problema ou conflito envolvendo os torcedores.

Próximo à entrada do estabelecimento existe uma máquina de música, e em todo jogo em que o Cruzeiro conquista uma vitória, Paulinho coloca o hino para tocar na máquina. Após o término das partidas, os torcedores permanecem por um tempo e conversam sobre o jogo, independentemente do resultado.

\subsection{Bar do João}

O Bar do João tem características parecidas com as do Bar do Paulinho. O bar fica na Rua Tomé de Souza, na Savassi, que, como se viu anteriormente, é uma região com a presença de muitos bares, cafés e restaurantes. Assim como o Bar do Paulinho, o Bar do João destoa dos demais bares da região. Em especial, por ser muito pequeno. $O$ estabelecimento conta com dois televisores. Durante as partidas, um deles é colocado na parede do bar na área externa. O segundo é fixo e fica acima do freezer de cervejas.

João é atleticano, e seu bar passou a ser um ponto de encontro de torcedores do Atlético. Existem no bar até mesmo algumas figuras, adesivos e pequenos objetos que remetem ao clube. No bar é possível acompanhar os jogos às quartas e quintas-feiras e aos sábados. Aos domingos, João não abre o bar.

Outra característica que se repete nos bares do Paulinho e do João é a presença de um grupo recorrente. Durante a pesquisa foi possível identificar que muitos desses torcedores estavam presentes em quase todos os jogos. Resumidamente, é possível afirmar que existem dois grupos no bar: os que acompanham os jogos na parte externa e um pequeno grupo que se espreme no interior do diminuto bar. Este último, nitidamente mais próximo do João, até mesmo com alguns deles ficando atrás do balcão, área comumente restrita ao comerciante. Em relação ao grupo externo, as conversas e comentários entre os torcedores sentados em diferentes mesas ocorrem a todo momento. Quando o Atlético faz um gol, muitos saem correndo e comemorando pela rua, além de confraternizarem com os outros torcedores presentes no bar com abraços e apertos de mão.

A interação entre os torcedores, o João e os garçons (dois que trabalham em dias de jogo) acontece em vários momentos durante as partidas. Observando mais detidamente a interação entre João e os torcedores, viu-se que uma torcedora, de aproximadamente 35 anos, frequentadora assídua do bar, mantinha uma prática bastante curiosa nas vezes que o Atlético sofria um ataque. 
Mais uma vez a prática da Torcedora se repetiu: assim que o Lanús parte para o ataque ela se vira em direção ao balcão e grita: 'Seguuura João!' Lá de dentro do bar, João responde apenas com um gesto; levanta a mão fechada, fazendo uma espécie de figa... (Caderno de campo dos autores. 23/07/2014. Durante a partida Atlético-MG x Lanús-ARG).

Nos bares que analisaremos a seguir, Galopé e Pompéu, a ideia de pedaço não se repete, o vínculo dos torcedores ali presentes com o bar é frágil. Contudo, há uma concentração maior de torcedores se compararmos aos dois primeiros. Existe ainda uma diferença em relação à manifestação dos torcedores neste espaço, mimetizando o comportamento dos torcedores nos estádios. A relação entre comerciantes e torcedores também muda, havendo aqui um distanciamento maior.

\subsection{Bar Galopé \& Cia}

O bar Galopé \& Cia se localiza na Avenida Dr. Cristiano Guimarães, no bairro Planalto, que faz parte da Regional Norte. O bar está em uma galeria, a loja não é grande, por isso os clientes ocupam a calçada do estabelecimento. A cozinha fica na sobreloja e o banheiro, que é comum para todas as lojas da galeria, fica nos fundos.

Existe outra organização, em dias de jogos, que foge à habitual. É observada toda uma rotina de preparação do bar. A calçada em frente ao estabelecimento fica abarrotada de mesas e cadeiras. É colocada no balcão e próxima à TV a bandeira do Atlético e, em alguns jogos, principalmente nos noturnos, um projetor é ligado para a transmissão que é feita na parede de uma loja vizinha. Em partidas importantes e com a expectativa de um grande número de clientes, ocorre uma mudança na dinâmica de venda de cerveja. Os clientes passam a ter que pagar no mesmo momento em que pedem a bebida, visando minimizar as perdas por parte do bar.

Em qualquer tipo de jogo, a maior parte dos torcedores se veste com a camisa do clube, levam bandeiras, sinalizadores, fogos e rojões. Essa intensa manifestação que acontece no Galopé reverbera em uma grande interação entre os torcedores, mas em menor grau em relação ao proprietário e aos demais funcionários do estabelecimento.

Próximo ao bar existe um prédio residencial em que, em dias de jogos do Atlético, quando a manifestação dos torcedores é mais intensa, alguns torcedores do Cruzeiro residentes desse edifício se mostram incomodados com o barulho dos cantos, das conversas, dos fogos e das comemorações. Se o adversário do Atlético marca um gol, esses moradores passam a se manifestar das janelas, em direção ao bar, fazendo provocações ao rival. Quando o contrário acontece, a situação se inverte:

O jogo estava muito equilibrado e o placar de zero a zero insistia em permanecer. A torcida presente no Galopé já não cantava e apoiava mais a equipe como no início da partida. A tensão tomava conta. No início do segundo tempo o Atlético voltou a pressionar, tentando aproveitar a expulsão de um jogador adversário. Porém, mesmo tendo um jogador a mais no gramado, aos 15 minutos sofreu 0 gol. Os moradores do prédio vizinho começaram a aparecer nas janelas e gritar: Chupa franga 6 ! Chupa franga! No bar os torcedores apenas reclamavam e 'cornetavam' alguns jogadores. A reação do Galo foi rápida e aproximadamente 2 minutos depois de sofrer o revés, Jô empatou a partida. Houve uma grande

6 Forma jocosa de tratamento dos torcedores cruzeirenses em relação ao atleticanos. Como o mascote do Atlético é o Galo, há essa substituição com o intuito de, simbolicamente, fragilizar ou diminuir o adversário. 
comemoração dos torcedores. Alguns torcedores estouraram foguetes. 0 jogo seguiu tenso, e faltando quatro minutos para o fim da partida o Atlético conseguiu a virada. Neste momento houve uma grande manifestação dos torcedores. Fogos foram estourados novamente. Muitos torcedores se levantam e correm em direção à rua se aproximam do prédio a fim de 'dar o troco' no rival. Muitos ficam gritando: Chupa Maria?! Chupa Maria!; Filho da puta! Aqui é Galo! Aqui é Galo! Porra. (Caderno de campo dos autores. 26/02/2014. Após a partida Atlético-MG x Santa Fé-COL).

O hino do Atlético e alguns cantos presentes nos estádios são constantemente entoados pelos torcedores. Assim, em certa medida, acabam mimetizando o arquétipo de torcedor mais comum nos estádios. Contudo, as conversas entre eles se prendem mais às questões táticas e técnicas do jogo. Durante as partidas, os torcedores se acomodam em frente às duas TVs. Um dos aparelhos é sustentado por um suporte que o mantém a uma altura suficiente para que todos assistam sentados.

\subsection{Bar Pompéu}

O Bar Pompéu fica localizado na Regional Pampulha, no bairro Itapoã, considerado de classe média. $\mathrm{O}$ bar recebe bom número de clientes, também em dias sem jogos de futebol.

0 estabelecimento tem uma característica que os outros bares da pesquisa não apresentam. Durante o dia, funciona como restaurante, tendo um amplo salão com mesas de madeira distribuídas pelo espaço. No cardápio, assim como no Bar do Paulinho, encontrase uma referência à transmissão dos jogos de futebol, utilizando para isso a logomarca do Premiere Futebol Clube ${ }^{8}$.

Outro fator que se destaca no Bar Pompéu é, em dias de partidas de Atlético e Cruzeiro no mesmo horário, o estabelecimento transmite os dois jogos. 0 espaço fica dividido entre os rivais. Uma barreira imaterial, invisível, é estabelecida pelos aparelhos de TV. Os televisores da esquerda transmitindo uma partida e os aparelhos da direita o jogo do rival. O bar conta com seis televisores, um deles é colocado na parte externa do comércio. Na calçada do estabelecimento são distribuídas algumas mesas e cadeiras, mas elas não são a preferência dos torcedores, ficando menos ocupadas em dias de jogos.

Em relação à forma de manifestação dos torcedores que vão ao Bar Pompéu, aproximase a observada no bar Galopé. Existe uma intensa comemoração quando acontece um gol. A intensidade dessa comemoração se acentua quando há jogos simultâneos de Atlético e Cruzeiro. Além da comemoração do êxito do próprio time, comemora-se também o fracasso do rival. Em uma partida das semifinais da Copa do Brasil, Atlético e Cruzeiro jogavam no mesmo horário. O Atlético sofreu um gol, quando necessitava reverter o placar e fazer três gols de diferença. Nesse momento, os torcedores do Cruzeiro, que acompanhavam a partida de seu clube contra o Santos, passaram a fazer provocações.

No momento em que o Atlético sofreu o gol, os torcedores do Cruzeiro começaram a fazer piadas e rir da situação do rival. E passaram a cantar: 'Eu acredito!' voltados para o lado Atleticano do bar. Ao final da partida o Atlético conseguiu

7 Codinome criado pela torcida atleticana como sinônimo de cruzeirense. Assim, como a torcida do Cruzeiro visa fragilizar ou diminuir o adversário. Interessante perceber que, em ambos os casos, transformar o 'outro' em um substantivo feminino é motivo de reafirmação de sua própria masculinidade e força.

8 Pacote adquirido junto às empresas de TV para transmissão dos jogos de um time específico ou de todo o campeonato. 
a classificação. Com a conquista, os Atleticanos 'retribuíram' as provocações, entoando o 'Eu acredito!" Uma boa parte dos torcedores se levantou das mesas e 'invadiu' o lado celeste do bar. (Caderno de campo do autor. 05/11/2014. Durante as partidas: Atlético x Flamengo e Santos x Cruzeiro)

Com o exposto do trecho acima, pode-se ver que o bar Pompéu permite que a rivalidade entre atleticanos e cruzeirenses seja vivenciada. Nesse sentido, a rivalidade é construída, segundo Damo (1998), pela representação simbólica e conquistas que cada clube detém. Sejam os longos períodos de supremacia de um clube frente ao rival, seja a maior torcida ou até mesmo um patrimônio maior ou mais valioso, dentre outros fatores que podemos elencar. Atentando-se para esses aspectos, o "outro" almeja o que por ele necessita ser conquistado. Com isso, a rivalidade se consolida, pois, além de conquistar o que o outro tem, é necessário, mesmo que simbolicamente, atenuar, empobrecer ou ignorar os pertences, materiais ou não, com o objetivo de enaltecer o seu próprio patrimônio ${ }^{9}$ (DAMO, 1998).

\subsection{Itatiaia Rádio Bar}

O Itatiaia Rádio Bar fica no bairro Carmo, situado na Rua Pium-í, região com índice socioeconômico elevado na capital mineira. Diferentemente dos demais bares, não nos foi permitida a aplicação dos questionários junto aos torcedores presentes. Desse modo os dados que possuímos advém de observações e anotações.

Entre todos os bares integrantes desta pesquisa, este apresenta o maior apelo comercial, acarretando um relacionamento mais impessoal entre os torcedores e os funcionários do bar. 0 bar pertence ao grupo empresarial dono da Rádio Itatiaia. Essa emissora é uma das principais na cidade e também no estado de Minas Gerais. Tem como um de seus maiores produtos a transmissão de partidas de futebol, sendo o futebol também o carro-chefe do bar.

Além da estrutura para a transmissão de jogos, o bar tem um palco e uma bancada de onde é possível realizar programas e entrevistas ao vivo para a emissora. Além disso, durante as transmissões das partidas, simultaneamente, é feita a transmissão pelo rádio.

O bar tem capacidade para 250 pessoas, distribuídas em dois andares. Vários televisores se encontram distribuídos pelo bar, aproximadamente dez aparelhos e três telões de alta definição.

Não observamos, durante a pesquisa, a existência de um grupo de torcedores que frequente assiduamente o estabelecimento. Assim com não vimos a existência de uma relação mais pessoal entre os frequentadores e os funcionários do bar.

Nos jogos em que estivemos presentes não notamos manifestações de muito entusiasmo. No momento em que acontecem os gols existe a comemoração contida dos torcedores.

Em relação ao Itatiaia Rádio Bar, é possível entendê-lo como um espaço, em comparação com os demais estabelecimentos, onde o modelo empresarial de entretenimento prevalece, lançando mão, para isso, do futebol e das transmissões dos jogos. A apresentação de programas da rádio no estabelecimento e a presença de DJs logo na sequência do término das partidas reforçam esse dado. Canclini (1997) nos fala de uma lógica de transformação 
da cultura em produtos. Como o futebol e o torcer, que têm grande importância simbólica e fazem com que o retorno financeiro seja muito provável. Entendemos esse caso como um bom exemplo da industrialização da cultura.

Em todos os bares pesquisados para este trabalho, é possível verificar um sentimento de divertimento coletivo, já apontado por Bale (2002). Ainda para esse autor, o bar, no contexto da assistência do futebol, está localizado simbolicamente entre o estádio e a casa do torcedor, permitindo comportamentos que são únicos nesse espaço, mas também fazendo aproximações com os dois extremos dessa trindade. A partir dessa contribuição, pontua-se que, ainda que todos os bares estejam entre o estádio e a casa do torcedor, eles apresentam características distintas uns dos outros.

Nos bares do João e do Paulinho, vê-se maior interação entre os torcedores, bem como com os proprietários. Por esse motivo, nesses dois espaços, são formados grupos de torcedores que regularmente se reúnem para acompanhar as partidas de seus clubes. Neste sentido, os bares podem ser considerados um pedaço, de acordo com a proposição de Magnani (2008), uma vez que, além do relacionamento entre os torcedores, há um relacionamento com o lugar. Concordamos com outro apontamento de Magnani (1998), quando salienta que esse conceito pode sofrer variações ${ }^{10}$ de acordo com o local da pesquisa, se central ou periférico. Caso que observamos neste trabalho.

Entendemos que na formação desse sentimento de pertencimento ao estabelecimento parece estar ligada a postura de seus proprietários. Ambos, além de comerciantes, se colocam explicitamente como torcedores. Essa identificação com outros torcedores é percebida e acaba estimulando uma frequência maior ao bar. Com esses encontros se tornando recorrentes, catalisam a sociabilidade e a formação de laços de amizade.

Ao analisarmos os bares Galopé e Pompéu, percebemos que ambos se configuram como um espaço de encontro para torcedores de futebol, mas ainda não é possível considerálos como pedaço. $O$ vínculo que ali se mantém é mais frágil. A pequena aproximação e a pouca colocação dos proprietários como torcedores comuns parecem impedir o estreitamento de laços dos torcedores entre si, dos torcedores com o estabelecimento e com seu proprietário. Porém, é possível entendê-los como bares onde existe a formação de grupos, de vínculos. Esses encontros, mesmo que efêmeros, são capazes de reunir várias pessoas, com características semelhantes, com objetivos semelhantes e a mesma paixão clubística.

\section{CONCLUSÃO}

O torcer no futebol e os bares são duas importantes manifestações de lazer para a população de Belo Horizonte. Ao longo de todo o período de pesquisa de campo, percebemos que o futebol e o torcer nos bares são significativos para a promoção do encontro das pessoas e para a interação social, fato que se repete desde os bairros mais desfavorecidos, até em bairros mais abastados da cidade. E essa não é uma relevância que deva ser subestimada. Entendemos que ainda precisamos avançar muito em relação às ofertas culturais e de lazer 
que são disponibilizadas e acessíveis à população. De certa forma, a "tabelinha" bar e futebol contribuem para a diminuição dessa carência.

Os proprietários dos bares pesquisados neste trabalho também consideram a transmissão dos jogos nos bares uma atividade importante para a sociabilização. Foi unânime também o destaque dado às transmissões de futebol no bar em termos econômicos. 0 aumento da margem de lucro é uma realidade apontada por todos os proprietários dos estabelecimentos que participaram desta pesquisa.

Em relação à forma de torcer nos bares, é possível afirmar que não existe um torcedor de bar e, sim, muitos e diferentes torcedores. Existem maneiras de se manifestar, de torcer nos bares, assim como em qualquer outro lugar. Sem o intuito de categorizar e rotular como se dá o torcer nos bares, contudo, concluímos que, genericamente, vimos três formas de manifestação do torcer. Um torcer mais comedido, no que se refere à fala dos torcedores. Poucas manifestações, xingamentos e interação entre os presentes. Realidade mais recorrente em um bar com um ambiente organizado, com alto investimento financeiro, atendimento eficaz, porém impessoal.

Existe também um torcer enfático, expressivo e entusiasmado, podendo, em muitos momentos, se tornar bastante parecido com o torcer nas antigas arquibancadas ${ }^{11}$. No entanto, com um vínculo entre os torcedores e entre torcedores e proprietários existindo em menor grau.

Outra forma de torcer que encontramos é o torcer caricatural. Não é explosivo como o segundo, tampouco frio como o primeiro. Esses torcedores são aqueles que reclamam, "cornetam", comentam, interagem muito entre eles e com os proprietários. Extravasam no momento de comemorar os gols, lançam mão de vocabulário chulo para expressar uma tristeza ou decepção. Alguns deles chegam a dar instruções para a TV com se estivessem à beira do gramado e pudessem ser ouvidos. Existe também a construção e a manutenção de uma forte relação entre os torcedores e entre o torcedor e comerciante. São formados grupos de torcedores, em que o dono do bar é mais um integrante.

Os torcedores buscam ir ao bar para ver um jogo de futebol, mas, além da partida, outros pontos são considerados e favorecem essa ida. $O$ encontro com os amigos é o mais citado. Ainda foram mencionadas em quantidade significativa a proximidade do bar e a amizade com o proprietário. O uso da bebida alcoólica tem destacado papel no contexto, sendo a cerveja a preferência dos torcedores. Ela, assim como o futebol e o torcer, é um fator que promove a sociabilidade.

Os torcedores que fizeram parte deste estudo demonstraram que a prática de lazer que foi objeto desta pesquisa é comum em vários bairros da cidade. Faz parte da cultura futebolística de pessoas que acompanham e têm o sentimento de pertencimento clubístico. A nosso ver, a movimentação nos bares em noites de quartas e quintas-feiras e tardes de sábados e domingos certamente já compõe a paisagem urbana da capital mineira.

\section{REFERÊNCIAS}

BALE, John. Virtual fandoms: futurescapes of football. In: BROWN, A. (Org.). Fanatics! power, identity and fandom in football. London: Taylor e Francis, 2002. p. 265-278.

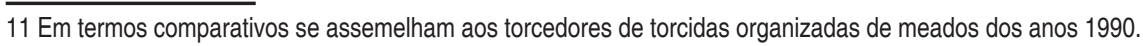


CANCLINI, Néstor García. Consumidores e cidadãos: conflitos multinacionais da globalização. Rio de Janeiro: UFRJ, 1997.

DAMO, Arlei Sander. Para o que der e vier: o pertencimento clubístico no futebol brasileiro a partir do Grêmio Foot-Ball Porto Alegrense e seus torcedores. 1998. 237 f. Dissertação (Mestrado em Antropologia Social) - Instituto de Filosofia e Ciências Humanas, Universidade Federal do Rio Grande do Sul, Porto Alegre, 1998.

DAMO, Arlei Sander. Do dom à profissão: a formação de futebolistas no Brasil e na França. São Paulo: HUCITEC, 2007. v. 1.

DIXON, Kevin. The football fan and the pub: an enduring relationship. International Review for the Sociology of Sport, v. 49, n. 3/4, p. 382-399, 2014.

GASTALDO, Edison Luis. Futebol e sociabilidade: apontamentos sobre as relações jocosas futebolísticas. Esporte e Sociedade, v. 1, p. 1-16, 2006.

MAGNANI, José Guilherme Cantor. Festa no pedaço: cultura popular e lazer na cidade. 2. ed. São Paulo: Hucitec/UNESP, 1998.

MAGNANI, Jose Guilherme Cantor. De perto e de dentro: notas para uma etnografia urbana. Revista Brasileira de Ciências Sociais. São Paulo. v.17. n.49. p. 11-29, 2002.

MAGNANI, Jose Guilherme Cantor. Na metrópole: textos de antropologia urbana. 3. ed. São Paulo: EDUSP, 2008.

MINAYO, Maria Cecília de Souza. (Org.). Pesquisa social: teoria, método e criatividade. Petrópolis: Vozes, 1994.

ORIGUELA, Milena Avelaneda. Futebol e cultura: assistência aos jogos em um bar na cidade de Piracicaba-SP. 2013. 92 f. Dissertação (Mestrado em Educação Física) - Faculdade de Ciências da Saúde, Universidade Metodista de Piracicaba, Piracicaba. 2013.

SALLES, José Bento Teixeira de. Rua da Bahia: do Estrela à Gruta, uma trajetória boêmia BH, a cidade de cada um. Belo Horizonte: Conceito, 2005. v. 4.

TORRES, Lilian de Lucca. Programa de paulista: lazer no Bexiga e na avenida Paulista com a rua da Consolação. In: MAGNANI, José Guilherme Cantor; TORRES, Lilian de Lucca.(Org.). Na Metrópole: textos de antropologia urbana. 3. ed. São Paulo: EDUSP; FAPESP, 2008. p. 54-87.

WEED, Mike. The Story of an Ethnography: the experience of watching the 2002 World Cup in the Pub. Soccer and Society, v. 7, n. 1, p.76-95, jan. 2006.

WEED, Mike. The pub as a virtual football fandom venue: an alternative to 'being there'? Soccer and Society, v. 8, n.2/3, p. 399-414, abr.jul. 2007.

ZAMBENEDETTI, Gustavo; SILVA, Rosane Azevedo Neves da. Cartografia e genealogia: aproximações possíveis para a pesquisa em psicologia social. Psicologia e Sociedade, v. 23. n. 3, p. 454-463, 2011. 
Apoio: CAPES 